Canadian Studies in Population, Vol. 35.1, 2008, pp. 1-26

\title{
Maternal Mortality in Nepal: Unraveling the Complexity
}

\author{
Juhee V. Suwal \\ Department of Family Medicine \\ University of Alberta \\ Edmonton, Alberta, Canada T6G 2C8 \\ jsuwal@ualberta.ca
}

\begin{abstract}
Maternal mortality has been recognised as a public health problem in the developing countries. The situation concerning maternal mortality in Nepal remained unexplored and vague until the early 1990s. By using 1996 Nepal Family Health Survey, this study discusses the maternal mortality situation in Nepal and analyses the differentials in maternal mortality by place of residence, region, ethnic and religious groups, age at death, and parity. Almost 28 percent of deaths of women in reproductive age was accountable to maternal causes. Logistic regression analysis shows 'ethnicity,' 'age of women,' and 'number of births' as strong predictors of maternal mortality. A number of policy recommendations are suggested to help lower maternal mortality.
\end{abstract}

Key Words: Nepalese women, maternal mortality, women's health, Logistic Regression, Demographic Health Survey 
Juhee Suwal

\section{Résumé}

La mortalité liée à la maternité est un des phénomènes de santé qui a été identifié dans les pays en voie de développement. La situation de la mortalité liée à la maternité au Népal est restée inexplorée et assez vague jusqu'au début des années 1990. En utilisant les données du Nepal Family Health Survey de 1996, cet article examine la situation de la mortalité liée à la maternité au Népal et analyse les différentiels des taux de mortalité par lieu de résidence, région, groupe ethnique et religieux, âge au décès, et parité. Presque 28 pourcent des décès de femmes en âge de procréer sont liés à la maternité. L'analyse de régression logique démontre que «l'ethnicité », «l'âge des femmes », et le «nombre de naissances » sont de forts prédicteurs du taux des mortalités liées à la maternité.

Mots-clés : Femmes népalaises, mortalité liée à la maternité, régression logique, santé des femmes, Demographic Health Survey

\section{Introduction}

Social scientists admit that maternal mortality is an important, complex, and neglected field of study in the developing countries, which has only in the late 1980s been recognised as a public health problem (Boerma, 1987; Graham et al., 1989; Basch, 1990). Estimation of maternal mortality levels is complicated, especially in a country such as Nepal where physical and health infrastructures are inadequate, and complex traditional cultures predominate. The Nepal Family Health Survey (1996) estimates Nepal's maternal mortality ratio (MMR) to be 539 per 100,000 live-births (Ministry of Health, 1997a), which was the highest among the South-Asian countries at that time (United Nations, 2000). ${ }^{1}$ The Demographic Health Survey (DHS) 2006 of Nepal shows its MMR as 281 per 100,000 live-births, a decrease by almost 50\% (Nepal Demographic and Health Survey 2006, 2007). All these years, the strategies to deal with high maternal mortality in Nepal have often been omitted from social and health development policies as in most other developing countries. Why has this happened? In this paper, relevant literature will be reviewed; the situation of maternal mortality in Nepal will be explored; and the available data will be analysed to examine the differentials in maternal mortality by age, parity, place of residence, region, ethnicity, and religion, and to determine what factors affect maternal mortality the most. 


\section{Causes of Maternal Deaths in Nepal}

Pregnancy and delivery-related causes are among the top ten reasons for death among women of reproductive age in almost all developing countries (Winikoff $\&$ Sullivan, 1987). The main direct causes of maternal mortality in Nepal are identified as haemorrhage (anti-partum, post-partum and abortion-related) and birth trauma (ruptured uteri, cephalo-pelvic disproportion and so on) (World Bank, 1989; Ministry of Health, 1998). Among these, haemorrhage was found to be the number one cause of death. Most maternal deaths (46.2\%) occurred during postpartum period (Ministry of Health, 1998). As reported by the World Bank (1989), complication of pregnancy, childbirth and puerperium was the number one cause of hospital admission in Nepal in 1980/81 and 1983/84 with 47 percent admissions accountable to this cause in the latter year. According to the traditional birth attendants from different ethnic backgrounds (interviewed for a study in 18 village development committees in Nepal), maternal deaths were mostly caused by bleeding, retained placenta, weakness, tetanus, lack of care, and supernatural causes such as exorcism and evil eye (Levitt, 1993). However, researchers admit that determining the actual causes of maternal deaths is often difficult even in hospitals (Boerma \& Mati, 1989). Maternal mortality is also caused indirectly by hepatitis, diabetes, malaria, infections, malnutrition, and anaemia. The indirect causes, though preventable, contribute to about 24 percent of all maternal deaths in the world (Weston, 1986).

\section{Factors that Affect Maternal Deaths in Nepal}

Traditionally, pregnancy is considered to be natural in Nepal. Thus, regular check-ups are thought to be unnecessary, particularly in rural areas, unless there are complications. A study by Suwal (2001) unveiled an interesting finding related to prenatal medical visits and infant mortality in Nepal. Infants were more likely to die if their mothers sought prenatal medical care while these infants were in the womb than those who did not seek prenatal care. This indicated an association between pregnancy complications and seeking prenatal medical care. Such norms were found in other developing countries as well. The Demographic Health Survey, 1991 of Egypt reported that $81 \%$ of women who sought prenatal care did so because of a medical problem in Upper Egypt (Abdulla et al., 1992). According to the Nepal Family Health Survey 1996, only 24 percent of the women interviewed received prenatal care, contradicting the report of the Ministry of Health (1996/97) that the achievement of maternal services including both antenatal and postnatal cares was 138 percent for the year 1996/97 (Ministry of Health, 1996/97). 
Juhee Suwal

Also, factors such as early marriages, frequent births (short birth intervals), and high parity create health hazards to Nepalese women. In rural areas, early marriage is traditional. The mean age at marriage for Nepalese women is as low as 19.5 years (Central Bureau of Statistics, 2006), was even lower at 18 years a decade ago (Central Bureau of Statistics, 1995). Early marriage also means early pregnancy and childbirth, both of which are harmful to very young women as their body may not be physiologically ready to bear children. Frequent births, then, entail repeated life-threatening processes. Moreover, some reports show that fifty percent of all maternal deaths in Nepal (where abortion was illegal until September 2002) were due to induced abortion (The Kathmandu Post, 1997). Unsafe, unhygienic and sometimes fatal nature of practices conducted by traditional birth attendants were the reasons for maternal deaths in such cases (Thapa et al., 1994).

Delay in seeking help due to problems of finance, transport, cultural beliefs, and decision making has been reported by a number of studies in Nepal (Carlough, 1997; Sigdel, 1998; Ministry of Health, 1998). Furthermore, many district hospitals are unable to cope with obstetric emergencies (Presern, 1992). Even in a country such as Vietnam where the healthcare system is claimed to be highly developed, causes like "blood not available," and "inaccurate diagnosis or treatment" were reported to be the reasons of maternal deaths (Hieu et al., 1999). Among other problems, drugs are not always readily available in the hospitals in Nepal, the concerned family has to purchase them, but most poor families are unable to do so. In addition, the health care staffs in the rural health posts are often reported as being unreliable, hostile towards local patients, and absent from the care centres (Justice, 1986; Niraula, 1994; Carlough, 1997; Sigdel, 1998), the major probable causes of not seeking medical care by rural women even when medical care was available. Moreover, sanitation, a factor that affects maternal mortality, is extremely poor in rural areas/homes. Unfortunately, almost all the deliveries in these areas take place at home (Ministry of Health, 1996/97).

Because traditional birth attendants (TBAs) can be found almost everywhere in the country (Levitt, 1993) and women consult them not only for delivery assistance but also for pregnancy complications, the role of TBAs and training them on safe birthing may become very important in the survival of women of reproductive ages. However, those women who cannot afford the money and gifts traditionally offered to TBAs do not have the opportunity to consult them. In such cases and in cases where women have no helpers at home, they even deliver alone. For these and other reasons, many women, unable to come into contact with TBAs, midwives or health workers, die unattended, often in agony (Presern, 1992). 
Culturally speaking, although women are highly respected for their reproductive role in the Limbu society of Nepal (Jones \& Jones, 1976); women represent as household-heads on account of their spouses' serving in foreign armies among the hill ethnic groups such as the Gurungs, the Magars, the Rais, and the Limbus (Jones \& Jones, 1976; Messerschmidt, 1976; Hitchcock, 1980); women are considered equals among the so-called low-caste people (Kipp, 1995) and mothers are highly regarded and have a special position in Newar families, in most ethnic groups women have little self-esteem and their status must not be higher than that of men. ${ }^{2}$ Whatever the invisible reasons, there are many factors that have a negative impact on Nepalese women's health and well-being, resulting in such overwhelmingly high figures for maternal mortality.

Unfortunately, the effect of all the interested factors on maternal mortality could not be tested in this study because of paucity of data. Based on the availability of data related to maternal deaths, an analysis of the relationship between maternal mortality and various socio-cultural and demographic variables was done in the current study. For analysis purposes, the following hypotheses were developed.

\section{Hypotheses}

1. The remoteness of different regions and the inadequate healthcare facility are life threatening to women experiencing reproductive stages in Nepal. Among the five development regions of the country, the Western Region of the country has relatively more medical facilities and women's empowerment index is the highest among other regions; the Kathmandu Valley, which has relatively high medical facilities, is situated under the Central Region; the Eastern Region is relatively prosperous with many industries; and the Far-Western Region is the most remote and the least developed of all the regions; the Mid-Western Region lies in between the Western and the Far Western regions in terms of health and development infrastructures (International Centre for Integrated Mountain Development, 1997; Ministry of Health, 1997b). Hence, it is hypothesised that compared to the Far-Western Region, all other regions will have higher chance of survival for women going through maternity process.

2. Because of the difficult terrain of the country and the remoteness of the villages, we hypothesise that women in the rural areas will have higher odds of dying due to maternal causes as opposed to urban women.

3. In Nepal, Buddhists and 'other' religious groups have more relaxed attitude towards gender roles compared to the orthodox Hindus (Bista, 1976). Buddhist women and women belonging to 'other' religions have higher status and autonomy than their Hindu counterparts. On the other hand, Muslim women are 
Juhee Suwal

found to have low status and autonomy in the family and the community (Bista, 1976). Such disparities may affect women's health, care for women during reproductive stages, and their access to healthcare facilities. Thus, the next hypothesis is "as opposed to Hindus, Buddhist women and women from 'other' religion will less likely, while Muslims will more likely die from maternal causes."

4. Ethnicity has shown a remarkable influence on the autonomy of women (Bista, 1976) and the literacy of women in Nepal (Central Bureau of Statistics, 1993). Because of different cultural practices (some with "mother-friendly" traditions) and life-styles of various ethnic groups in Nepal, women from different ethnic backgrounds may have varied reproductive experiences that may affect their survival. Since the Brahmins and the Chhetris have orthodox cultural background (Bista, 1976; Bennette, 1983), the Newars have a nurturing prenatal and postnatal traditional practice ${ }^{3}$, Mongoloid women are treated as equals by men (Bista, 1976; Jones and Jones, 1976; Hitchcock, 1980; Fricke, 1986; Thapa, 1996), occupational caste (also known as untouchable caste) women are well treated by their spouses (Kipp, 1995), and Muslims want as many children as possible (The Kathmandu Post, 1999) and Muslim women have less autonomy than those from other groups (Bista, 1976; Neidell et al., 1998 ) it is hypothesised that women belonging to Newars, Mongoloid groups, and occupational castes will have lower probability of maternal deaths, while Muslim women will have higher probability compared to Brahmins and Chhetris. ${ }^{4}$

5. Very young women going through reproductive process may experience complications because of lack of experience and not fully developed body. On the other hand, older women in age group 35-49 may have complications during child-bearing process for reasons such as tightening of muscles and hardening of bones, and other ailments of ageing such as hypertension and so on. Thus, the next hypothesis is "relative to women 35-49 years old, women aged 12-19 will more likely die during the reproductive process, while women 20-34 years of age will less likely die due to maternal causes."

6. High number of births has been linked to high maternal deaths in the developing world, especially postpartum deaths related to haemorrhage (Hay, 1999). As reproductive process is a complex phenomenon, repeated processes of this event may be life threatening to women. Hence it is hypothesised that as opposed to women who have had 4 or more births, those who had ' 0 ' births, 1 birth, 2-3 births will have lower odds of dying due to maternal causes. 


\section{Data and Methodology}

The data for this study were from the Nepal Family Health Survey (NFHS) 1996, which was the latest national data available on maternity deaths. The Demographic Health Survey 2006 data of Nepal, where questions on maternal deaths were included (unlike DHS 2001 where maternal mortality questions were not included), is not yet available for researchers.

The primary sampling unit (PSU) for NFHS 1996 survey was a ward or a group of wards in rural areas and sub-wards in the urban areas. The 75 administrative districts of Nepal were divided into Village Development Committees (VDCs) that were subdivided into wards and sub-wards. Altogether 253 primary sampling units were selected: 34 in the urban areas and 219 in rural. The sampling unit was the ever-married woman who was in the age group 15 to 49 years at the time of the survey. The total number of eligible women interviewed was 8,429 of which $712(8.45 \%)$ women came from urban areas and 7,717 (91.55\%) from rural (Ministry of Health, 1997a). The information on maternal mortality was collected by the sibling survival method. That is, the eligible respondents in the survey were asked about the characteristics and survival of their siblings. For this survey, maternal deaths were defined as deaths that occurred during pregnancy, childbirth or within two months after birth or termination of a pregnancy (Ministry of Health, 1997a).

Cross tabulations were computed between the social, demographic, and geographic variables and maternal deaths. In the second section, effects of different regional, spatial, demographic, ethnic, and religious factors on maternal mortality were analysed by using Logistic regression. The dependent variable was dichotomous in nature; it was the ratio of women (12-49 years old) dying of maternal causes versus women dying of other causes (the cut-off age for Nepal in this survey was 12 years for those siblings who died of reproductive complications).

The independent variables were region, place of residence, religion, ethnicity, age at death, and the number of child/children given birth by the sibling before she died. The background information of siblings such as ethnicity, religion, place of residence and so on was assumed to be the same as those of corresponding respondents'. The measurements of variables and dummy coding are shown in Appendix 1. For more clarification, 'ethnicity' for this study consists of six groups (those with similar culture were combined as a single ethnic group): 'Brahmin and Chhetri' (the so-called high caste groups), 'Newar' (the indigenous inhabitants of Kathmandu Valley), 'Mongoloid' (five hill ethnic groups the Gurungs, the Magars, the Rais, the Tamangs, and the Limbus were included in this group), 'Muslim and Churaute' (both of Muslim background), 
Juhee Suwal

'Occupational caste' group (the Kamis, the Sarkis, and the Damais, the so-called untouchables from the hills), 'Tharu, Rajbansi, Yadav, and Ahir' (well-known Terai origins) and all other Terai origins and other hill origins as 'other.'

\section{Findings}

\section{Descriptive Results}

Altogether, $26.3 \%$ of siblings died, of which $13.5 \%$ were males and $12.8 \%$ were females (Table not shown). Table 1 shows that among the dead female siblings, 1,016 were in the age group $12-49$ years. In total $27.9 \%(\mathrm{~N}=284)$ of these women died from all maternal causes, including pregnancy, delivery, and within 2 months after delivery. If we consider only the deaths during pregnancy and childbirth, the percentage dead in that age group was 14.5. Of the total deaths in that age group, $22.2 \%$ of deaths in the urban and $28.2 \%$ of deaths in the rural areas were attributed to maternal causes. The percentage differentials of deaths by region were marginal. However, the percentage of deaths during pregnancy and delivery only was the lowest $(9.6 \%)$ in the Western Region. The differentials among ethnic groups were substantial. The percentage of women who died of maternal causes was the highest for the Muslims (34.2\%) and the second highest for the "all Terai origins" (30.9\%). ${ }^{5}$ Mongoloid group had the lowest percentage of deaths due to maternal causes (19.0\%), second lowest being that for the Other hill origin (25.8\%). Among the religious groups, $17.1 \%$ deaths of Buddhist women in that age group were from maternal causes, which was also the lowest percentage among all the religious groups, whereas $34.2 \%$ deaths of Muslim women were accountable to maternal causes, which was not only the highest but also double the percentage dead for Buddhist women.

The deaths of women from maternal causes in different age groups (column 5, Table 2) depicted a higher percentage $(58.1 \%)$ of women dying in the middle age group 20-34 as opposed to the younger group (26.9\%) and the older group $(14.9 \%)$. Similarly, maternal deaths during specific periods such as pregnancy, delivery, and postpartum periods also showed the highest percentage of deaths for middle age group in each period (columns 2, 3, and 4, Table 2). This finding was not unexpected because more women in age group 20-34 were likely to get married and then conceive than the younger or the older groups.

The figures from Table 3 revealed the numbers and percentages of those who died of maternal causes by age groups and the number of child/children they had given birth to before they died. Most women from the youngest age group $(50.6 \%)$ died after $1^{\text {st }}$ child birth, most from $20-34$ age group (44.9\%) died after 
giving birth to 2-3 children, and the highest percentage from the oldest group $(63.4 \%)$ died after four or more births.

\section{Logistic Regression Results}

When the independent variables were entered separately one at a time, regions did not show any significant impact on women's dying of maternal causes against other causes. Similarly, whether women lived in urban or rural areas did not make any difference in dying of maternal causes or other causes (Table 4).

Among the religious groups, compared to Hindu women, Buddhist women were less likely to die due to maternal causes by a multiplicative factor of 0.535 or by 47 percent. Mongoloid women were $44 \%$ less likely to die from maternal causes as opposed to Brahmin and Chhetri women. Women who died at age 20-34 were almost twice as likely to die due to causes related to reproductive complications as those who died at age $35-49$.

Women who had never given birth (meaning pregnant women) were almost $56 \%$ less likely to die from maternal causes compared to those who had given birth to four or more children before they died. On the contrary, women who had given birth to one child were 2.4 times more likely to die from maternal causes compared to those who had given birth to four or more children before they died.

When the effect of each predictor variable was singled out by controlling effects of other variables, the influence of "ethnicity," "age at death," and "number of births given by a woman before she died" on dependent variable all still showed significant results (Table 5). However, the effect of religion disappeared from the scene.

Mongoloid women were still $49 \%$ less likely to die of reproductive complications compared to Brahmin and Chhetri women even when all other effects were considered. Women who died at age 12-19 were twice likely to die because of reproductive complications, so were those who died at age 20-34, as against those who died at age 35-49. 
Juhee Suwal

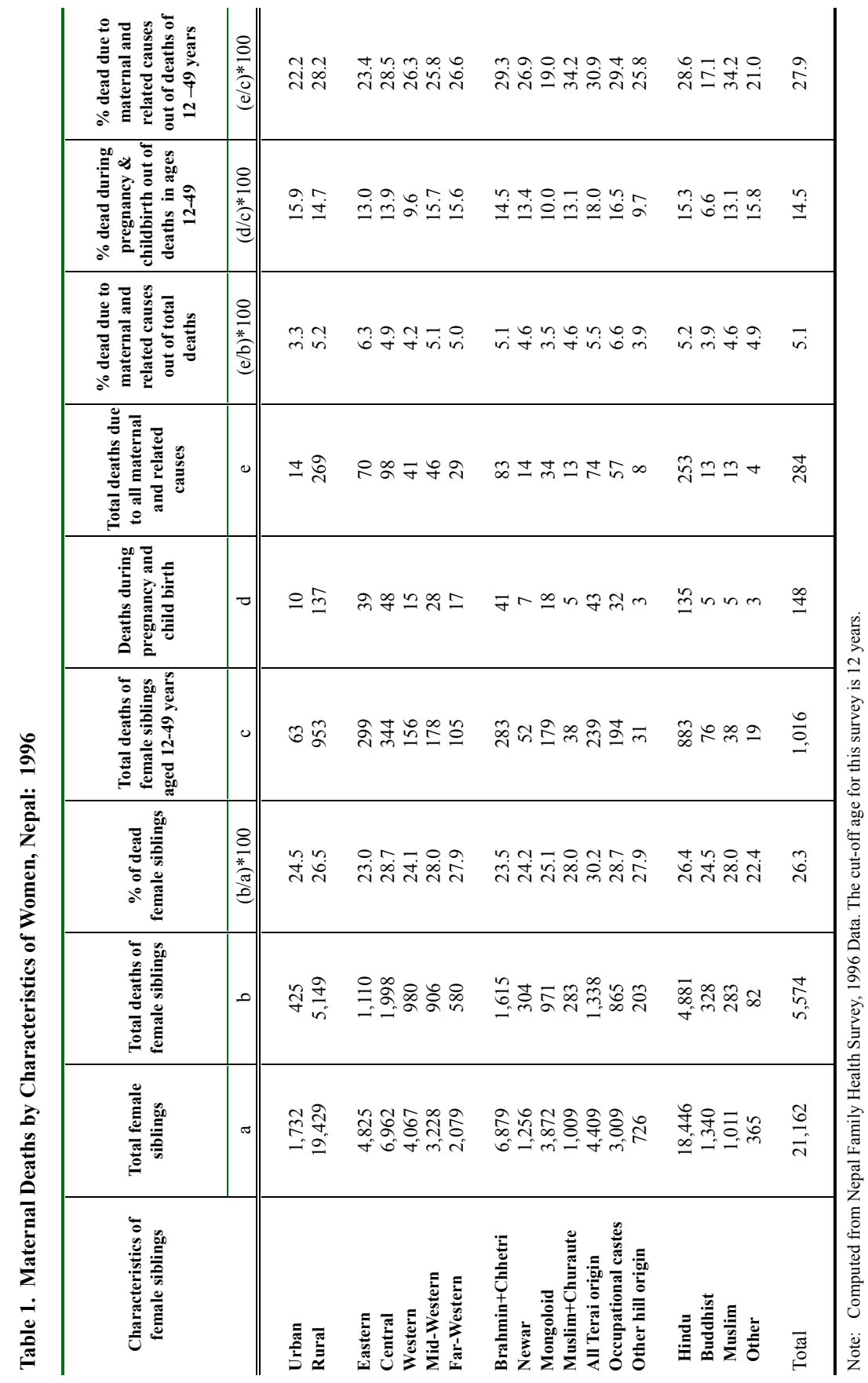


Maternal Mortality in Nepal: Unraveling the Complexity

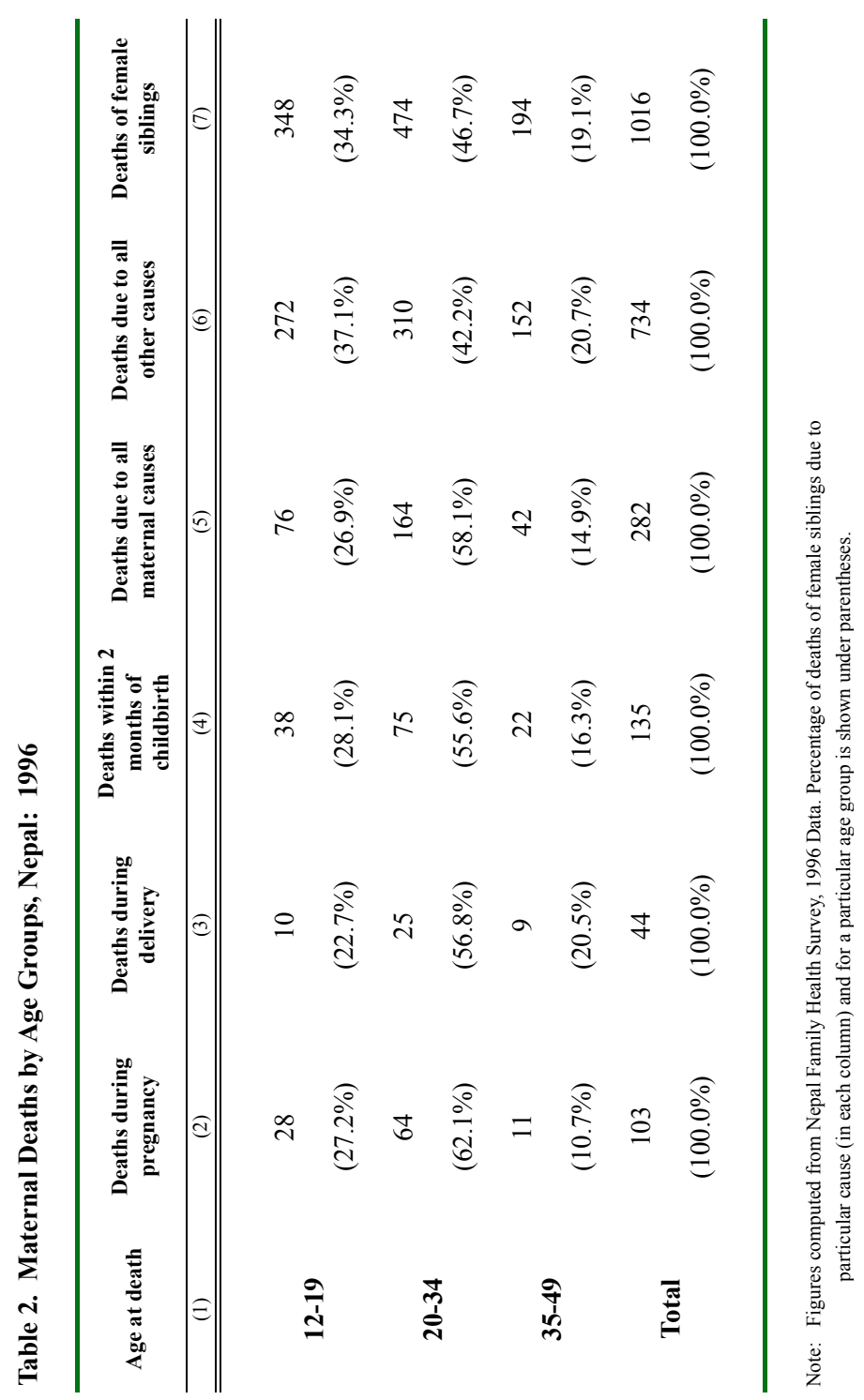


Juhee Suwal

Table 3

Maternal Deaths by Age Group and Parity, Nepal: 1996

\begin{tabular}{|c|c|c|c|c|c|}
\hline \multirow[b]{2}{*}{ Age at death } & \multicolumn{5}{|c|}{ Number of deaths due to maternal causes to women who had given birth to } \\
\hline & '0' child & 1 child & 2-3 children & $\begin{array}{l}4 \text { or more } \\
\text { children }\end{array}$ & Total \\
\hline$(1)$ & (2) & (3) & (4) & $(5)$ & (6) \\
\hline $12-19 *$ & $28(36.4 \%)$ & $39(50.6 \%)$ & $10(13.0 \%)$ & - & $77(100 \%)$ \\
\hline $20-34$ & $23(13.9 \%)$ & $39(23.6 \%)$ & $74(44.9 \%)$ & $29(17.6 \%)$ & $165(100 \%)$ \\
\hline $35-49$ & $1(2.4 \%)$ & $2(4.9 \%)$ & $12(29.3 \%)$ & $26(63.4 \%)$ & $42(100 \%)$ \\
\hline Total & $52(18.3 \%)$ & $81(28.5 \%)$ & $96(33.8 \%)$ & $55(19.4 \%)$ & $284(100 \%)$ \\
\hline Note: & $\begin{array}{l}\text { mputed from } \mathrm{Ne} \\
\text { he cut-off age of } \\
\text { indicates "no de }\end{array}$ & $\begin{array}{l}\text { Family Health } \mathrm{Su} \\
\text { nale siblings for } \mathrm{P} \\
\text { s." }\end{array}$ & $\begin{array}{l}\text { ey, } 1996 \text { Data. } \\
\text { pal in this survey w }\end{array}$ & 12 years. & \\
\hline
\end{tabular}


The effects of number of births still depicted a similar picture as in Table 4 even when effects of other variables were held constant. Women who had never given birth were $70 \%$ less likely to die of maternity complications compared to those who had four or more children before they died. On the other hand, those who had one child versus those who already had four or more children before their death were $78 \%$ more likely to die of maternal causes than other causes.

\section{Discussion}

Although not all hypotheses were supported, there were a number of highly significant and interesting results. First of all, there is a clear message that the risk of dying is not over for Nepalese women after the pregnancy and delivery stages. The vulnerability of complications and dying exists within two months after the delivery. Other studies also report that more than half of maternal deaths occur in the postpartum period (Li et al., 1996; Ministry of Health, 1998) and that most postpartum deaths in the developing countries including Nepal occur within six hours to seven days of delivery (Ministry of Health, 1998). The overall health condition of women may become very delicate for a few days after the delivery. In addition to her usual household and outside work, and the delicate health, she has a baby to look after and breastfeed during the postpartum period. How a woman's health, pregnancy, and delivery were handled and cared for may have a great impact on the complications or non-complications during postpartum period and thus, survival of these women.

Furthermore, almost $80 \%$ of women still give birth at home in Nepal. Complications of postpartum period may not be recognised by the family members, or may recognise only when the situation has gone from bad to worse. A study done in Vietnam found that maternal mortality was associated with home delivery (Hieu et al., 1999). Although we could not test empirically, the highest number of deaths in the post-delivery stage in Nepal might be associated with the delay in seeking care, reaching care, and providing care. Some of these women who died may not have had chance to seek medical care at all. A similar conclusion could be drawn for pregnancy-related deaths that were also substantial in number and percentage compared to those related to delivery. 
Juhee Suwal

Table 4

Logistic Regression on Maternal Mortality with Predictors

Entered One at a Time, Nepal: 1996

\begin{tabular}{|c|c|c|c|}
\hline Variables & B & Exp. B & Significance \\
\hline Region (Ref. Far Western) & & & 0.865 \\
\hline Eastern & 0.185 & 1.202 & 0.478 \\
\hline Central & 0.091 & 1.095 & 0.713 \\
\hline Western & -0.011 & 0.989 & 0.970 \\
\hline Mid-Western & -0.024 & 0.976 & 0.930 \\
\hline Constant & -1.018 & 0.361 & 0.000 \\
\hline Place of residence (urban) & -0.280 & 0.756 & 0.756 \\
\hline Constant & -0.934 & 0.393 & 0.393 \\
\hline Religion (Ref. Hindu) & & & 0.143 \\
\hline Buddhist & -0.625 & 0.535 & 0.044 \\
\hline Muslim & 0.273 & 1.314 & 0.435 \\
\hline Others & -0.459 & 0.632 & 0.421 \\
\hline Constant & -0.913 & 0.401 & 0.000 \\
\hline Ethnicity (Ref. Brah+Chhe) & & & 0.100 \\
\hline Newar & -0.130 & 0.878 & 0.702 \\
\hline Mongoloid & -0.580 & 0.560 & 0.012 \\
\hline Muslim & 0.234 & 1.263 & 0.523 \\
\hline Occupational castes & -0.016 & 0.984 & 0.937 \\
\hline Others & 0.052 & 1.053 & 0.781 \\
\hline Constant & -0.873 & 0.418 & 0.000 \\
\hline Age at death (Ref. 35-49) & & & 0.000 \\
\hline $12-19$ & 0.023 & 1.024 & 0.914 \\
\hline 20-34 & 0.655 & 1.926 & 0.001 \\
\hline Constant & -1.287 & 0.276 & 0.000 \\
\hline No. of births (Ref.4 or more) & & & 0.000 \\
\hline 0 births & -0.810 & 0.445 & 0.000 \\
\hline 1 birth & 0.870 & 2.386 & 0.000 \\
\hline 2-3 births & 0.253 & 1.287 & 0.210 \\
\hline Constant & -0.961 & 0.383 & 0.000 \\
\hline
\end{tabular}


Maternal Mortality in Nepal: Unraveling the Complexity

Table 5

Logistic Regression on Maternal Mortality with Effects of Other Predictor Variables Controlled, Nepal: 1996

\begin{tabular}{|c|c|c|c|}
\hline Variables & B & Exp. B & Significance \\
\hline Region (Ref. Far Western) & & & 0.391 \\
\hline Eastern & 0.412 & 1.510 & 0.151 \\
\hline Central & 0.190 & 1.210 & 0.496 \\
\hline Western & 0.079 & 1.082 & 0.795 \\
\hline Mid-Western & -0.027 & 0.973 & 0.926 \\
\hline Place of residence (urban) & -0.134 & 0.874 & 0.692 \\
\hline Religion (Ref. Hindu) & & & 0.930 \\
\hline Buddhist & -0.190 & 0.827 & 0.658 \\
\hline Muslim & 0.143 & 1.154 & 0.716 \\
\hline Others & -0.284 & 0.753 & 0.667 \\
\hline Ethnicity (Ref. Brah+Chhe) & & & 0.331 \\
\hline Newar & -0.214 & 0.808 & 0.570 \\
\hline Mongoloid & -0.660 & 0.517 & 0.037 \\
\hline Occupational castes & -0.079 & 0.924 & 0.718 \\
\hline Others & -0.064 & 0.938 & 0.756 \\
\hline Age at death (Ref. 35-49) & & & 0.003 \\
\hline $12-19$ & 0.704 & 2.021 & 0.014 \\
\hline 20-34 & 0.745 & 2.107 & 0.001 \\
\hline No. of births (Ref. 4 or more) & & & 0.000 \\
\hline O births & -1.199 & 0.302 & 0.000 \\
\hline 1 birth & 0.581 & 1.788 & 0.038 \\
\hline 2-3 births & 0.048 & 0.953 & 0.977 \\
\hline Constant & -1.296 & 0.274 & 0.000 \\
\hline Log-likelihood & 1105.611 & & \\
\hline Model Chi-square & 97.241 & & 0.000 \\
\hline d. f. & 17 & & \\
\hline $\mathbf{N *}$ & 1016 & & \\
\hline
\end{tabular}

${ }^{*} \mathrm{~N}$ is the number of female siblings who died at age $12-49$, from maternal causes and other causes. 
Juhee Suwal

Some of the studies mentioned in the text also acknowledged that maternal deaths could have been avoided to a large extent with appropriate care (Okonofua et al., 1992; Ministry of Health, 1998; Hieu et al., 1999). One of the reasons for delayed seeking in medical care may have been because of rural people's belief in Nepal. They may believe that the complication is created by an evil eye and thus, may seek help from shamans first (such beliefs may exist in some urban areas to some extent). ${ }^{6}$ However, for rural women to seek medical help, the current condition of health centres needs a radical change: the healthcare staff should be available in the centres whenever needed, in other words, health centres should be able to provide around the clock service; women need to be treated well by the staff (most of whom come from urban background); and health centres need to be well equipped for maternity emergencies.

Most women who did not seek antenatal care gave the reason for not seeking as "unaware of benefits of antenatal care" (Ministry of Health, 1998). Thus the formal and informal classes on prenatal and postpartum care should be number one priority in the country. Also, since women need to be physically fit to go through reproductive processes, highly nutritious food and physical movement are essential for them. Women may eat adequate food during pregnancy and postpartum period but the food they consume may not be nutritious. One of the important things the awareness classes should teach is about the nutritional information of different kinds of balanced food, nutritious as well as affordable. Moreover, because haemorrhage was found to be the number one cause of maternal deaths in Nepal and because haemorrhage is related to anaemia, food rich in iron should be strongly recommended. Women do preserve different vegetables and foods for off season all over the country. ${ }^{7}$ Even so, they may not know what the best foods are for a pregnant woman. On the other hand, most women may have enough physical movement during pregnancy because of their household chores and field work. In addition to such classes, girls' formal schooling also becomes important to develop awareness and knowledge. A detailed cause of postpartum deaths and its relationship to the complications during pregnancy and delivery should be studied urgently. If the postpartum deaths were indeed related to pregnancy complications, then antenatal care and women's overall health improvement become even more important.

Logistic regression results demonstrate that being a Mongoloid woman confers a reduced chance of dying from maternal causes as compared to Brahmin and Chhetri women. Religion, however, shows only a weak effect and possibly mediates through other social and demographic variables in having an impact on maternal deaths. Younger married women were more likely to die due to reproductive causes than those who were aged 35-49. Compared to women who had four or more children, the odds of dying during reproductive process were 
higher for women who had already given birth to one child, but the odds of dying were low for those who had not given birth yet. This implies that Nepalese women were at risk of dying after the first birth but not necessarily during the first pregnancy. This finding is in line with the Egyptian study (Abdullah et al., 1992).

Most importantly, maternal mortality is strongly associated with young age of mothers. Marrying early, consequently, conceiving early is taking more lives of women than Nepalese realise. Sending young girls off in marriage is a big relief in some cultures such as in the Terai plains of Nepal where dowry and tilak are compulsory and where the tilak amount goes higher as unmarried girls grow older. ${ }^{8}$ Chastity of girls and intra-caste marriages are given a high priority in the Newar culture and perhaps in some other cultures and thus, parents may want to marry girls off sooner than later among such cultural groups for the fear of young unmarried daughters having affaires with men, especially with men from different castes. For Brahmin fathers, giving away a young daughter (Kanyadaan, literally meaning "virgin give-away") means opening up the door to heaven. All these social customs may be affecting maternal mortality indirectly. Encouraging women to marry late and to use contraceptives for conceiving later may save many lives. One way to prevent early marriage is to educate girls compulsorily. Educated girls tend to marry late in Nepal like in other countries. Educated girls seem to be bold enough to oppose their early marriage. ${ }^{9}$

The relationship between parity (number of births) and maternal mortality, as seen from this research, is somewhat complicated. This study does not confirm the usual findings from other developing countries where high parity has been associated with high maternal mortality. What it confirms is the fact that in a country where pregnancy is not considered a 'disease' like in many developed countries, where women are not compulsorily taught antenatal and postnatal care by medical personnel, and where medical facilities are out of reach for most rural population, women's reproductive experience may be valuable to a great extent. The message here is that women's own reproductive experience has a beneficial effect on reducing their mortality related to reproduction. It is important to keep in mind that this finding is not to be misinterpreted as "high parity lowers maternal mortality."

Life-style and different cultural practices of various ethnic groups showed a remarkable impact on maternal mortality. Mongoloid women's almost $50 \%$ lower probability of dying of maternal causes compared to orthodox Brahmin and Chettri women supports the "women's empowerment" theory strongly. Is it only the high status and autonomy of Mongoloid women, their late age at marriage, and the affection and respect their spouses and family members give them or are there other factors such as nutrition and lifestyle that affect their 
Juhee Suwal

mortality related to reproduction, are some questions worth exploring in the future for more clarification. Learning from such cultures and sharing the ideas may help in reducing maternal deaths on national level in the long run. On the other hand, women's empowerment in reproductive health may not apply in a similar way to complex societies such as those of Nepal's. A recent study done in Kathmandu suggests that both husband and wife's joint decision on reproductive health resulted in husbands' cooperation in antenatal visits and women's health matters rather than when decision was made solely by a wife (Mullany et al., 2005).

Even though the Nepal DHS 1996 data did not allow us to analyse the relationship between healthcare-related factors and maternal mortality, it appears that preventive-care plays an important part in the survival of women during reproductive process. The descriptive findings suggest that the availability of health care facilities affect women's survival or death. Since curative health care is limited in Nepal for most rural population, preventive measures become even more important. If adequate precaution is taken beforehand, reproductive risks may be reduced substantially. Estimates show that $70 \%$ of the patients who appear in clinics or hospitals in Nepal have problems that could have been prevented (Journal of Nepal Medical Association, 1994). Also, because mothers-in-law, traditional birth attendants (TBAs), husbands (in most ethnic groups, husbands or any other males are not allowed in the delivery room), ${ }^{10}$ other female relatives, and neighbours attend labour and deliveries, educating and training them on maternal health needs to be emphasised. The TBAs and relatives of pregnant women should refer highrisk women to hospitals in time rather than handling the problem by themselves. Just as the nation-wide TBA training programme held during the 1980s (Levitt, 1993) was important, evaluation and further improvement of such programmes become essential for better outcomes. Training of Female Community Health Volunteers (FCHVs) in mid-wifery may be yet another way to save women's lives. With fee-for-service kind of incentives to the volunteers, such programmes may turn out to be highly feasible. Since more women are dying during postpartum period than during pregnancy and delivery stages, training and classes should emphasise on postnatal care besides women's overall health, especially the care for seven critical days of postpartum period.

Programmes such as refresher training to traditional birth attendants, "CheliBeti" programme (programme for girls/women), and evening classes seem to bring about a change in the attitude of women in Nepal. In those places where such programmes were conducted, women were more open about the concept of assisting mothers during and after delivery rather than letting women to deliver babies alone (Thapa, 1996). In addition, programmes on adult literacy and health, and maternal education for mothers-in-law have been found to be very 
successful in improving knowledge and practices concerning maternal care and in reducing maternal risk factors (Dali et al., 1992). The focus on educating mothers-in-law could be very influential because in most ethnic groups, it is them who decide on women's seeking medical help and on other matters related to daughters-in-law's needs and activities. ${ }^{11}$

\section{Conclusion}

Maternal mortality is a serious public health problem in Nepal as in other least developed countries. In Nepal, 5 women died for every 1000 child-births during 1990-1996. In spite of this alarming figure, maternal mortality, a problem of women, appears to have been long neglected as were their other problems. The problem of high maternal mortality was noticed by the Nepalese development planners and health experts only a few years ago. Research on maternal mortality was rarely done, thus information on this topic was not available and so the severity of the problem was not known until recently. Many women have been dying of preventable causes in Nepal, especially those women who die of reproductive causes. Pregnancy and giving birth should have been a time of rejoicing; unfortunately, for many it has too often been a time of mourning. Among other findings, this study indicates that women's empowerment and higher age at marriage may save many lives of Nepalese women.

Communication between the different sectors of the government such as health, planning, and population to enhance community development seems to be crucial. In a country such as Nepal where rural and urban disparities in terms of health facilities and lifestyle are highly polarized, specific community-based programmes are needed as had found by Bolan and colleagues in 1998. The effort of only one sector may not be sufficient in improving the reproductive health and thus bringing down maternal mortality. The collective effort of different sectors of the government of Nepal in maternity health and maternity care appears to have helped in lowering MMR recently as shown by the report of Nepal DHS 2006. According to the deputy health administrator of the Ministry of Health and Population, such results may have been possible due to the increased contraceptive prevalence rate, the decreased anaemia among pregnant women because of free distribution of iron capsules, the abortion facilities in almost all districts of the country since the legalization of abortion five years ago, the cash allowance for women who deliver babies in health institutions, and the increase in health budget (from about 3.5\% to $6.4 \%$ of the National Budget) from the government two years ago (Rijal, 2006). Furthermore, the decrease in total fertility of Nepalese women to 3.1 and infant mortality to 48 per 1,000 live-births in 2006 (2006 Nepal Demographic and 
Juhee Suwal

Health Survey: Fact Sheet, 2007) may have played a significant indirect role in the improvement of maternal mortality.

Moreover, the ideas and experiences of rural women should be considered seriously while developing the reproductive health programmes. The authorities need to emphasise not only in implementing of reproductive health programmes but also on keeping track of their success rates and drawbacks. Although there is no doubt that implementing such programmes will help reduce the existing maternal mortality problem, continuity of such programmes is essential for successful outcomes.

\section{Limitations}

There are some limitations of this study. First of all, similar to what previous researchers (Shiffman, 2000) had acknowledged, measuring maternal mortality proved to be a difficult process because of small sample size of deaths as a result of rarity of maternal deaths. In addition, the question asked about the causes of death of sisters in this survey generated a dichotomy such as "deaths due to maternal causes versus other causes," which made our analysis complicated. Thus, one needs to be cautious while interpreting the results.

Throughout this research, lack of study on postpartum mortality was noted not only for Nepal but also for other developing countries. In general, many more in-depth studies are needed at the national level to analyse the socio-cultural, socio-economic, demographic, geographic, and health care factors on maternal mortality. Questions concerning detailed causes of death, numbers of antenatal visits, nutrition, income, education, occupations, age at first birth, miscarriages, prevalence of contraceptive use, birth intervals, health care and work load of newly mothers should be included in future surveys related to maternal mortality. Because of the diversified cultural practices and social norms that may have direct or indirect effects on women's health and mortality, studies should be done separately for major ethnic groups of Nepal. For this to happen, the sample size of surveys related to maternal deaths should be large enough for analysis by major ethnic groups. The combination of some of the major ethnic groups (for example, combining the Rais, the Magars, the Gurungs, the Tamangs, and the Limbus as one Mongoloid group) may not be justified because of their varying cultures and lifestyles that could affect their mortality. 


\section{Acknowledgements:}

The author wishes to thank the Macro International Inc., Maryland, USA for providing the survey data on Nepal and acknowledges the help of Mr. Chuck Humphrey of the Data Library, Mr. Dave Odynak of the Population Research Laboratory, and Mr. Dave Clyburn of the Academic Support Centre, and the suggestions given by Dr. Linda Ogilvie of the Department of Nursing, Dr. Frank Trovato of the Department of Sociology, Dr. N. M. Lalu (currently retired) of the Population Research Laboratory, University of Alberta, on the earlier version of this paper.

\section{End Notes:}

1. For information, the MMR figure of 740 per 100,000 live-births for Nepal as reported by the WHO and the UNICEF was based on projections with assumptions on social indicators rather than based on a real study (Rijal, 2006).

Also, high maternal mortality could be the main reason behind the lower life expectancy at birth for women than for men in Nepal for many years. The life expectancy changed in favour of females since 2001 (Central Bureau of Statistics, 2006).

2. Newars are the aboriginals of the Kathmandu Valley.

4. Muslims are the ethno-religious group in Nepal.

5. Terai is the flat land situated in south Nepal all along the border of India.

8. Tilak is the amount of money and materials given compulsorily to the groom in most Terai cultures, while dowry is the gifts for the daughter during her wedding, a tradition in most cultures of Nepal.

$2,3,6,7,9,10,11$. Discussions based on the author's experience and observation in Nepal. 
Juhee Suwal

References:

Abdullah, S. A., E. M. Aboloyoun, H. Abdel-Aleem, F. M. Moftah, and S. Ismail. 1992. "Maternal mortality in Assiut." International Journal of Gynaecology and Obstetrics 39: 197-204.

Basch, P. F. 1990. Textbook of International Health. Oxford University Press, New York.

Bennett, Lynn. 1983. Dangerous Wives and Sacred Sisters. New York: Columbia University Press.

Bista, Dor Bahadur. 1976. People of Nepal (3rd Edition). Kathmandu, Nepal: Ratna Pustak Bhandar.

Boerma, J. T. 1987. "Levels of maternal mortality in developing countries." Studies in Family Planning 18 (4): 213-221.

Boerma, J. T. and J.K.G. Mati 1989. "Identifying maternal mortality through networking: Results from Coastal Kenya." Studies in Family Planning 20 (5): 245-253.

Bolam A., D.S. Manandhar, P. Shrestha, M. Ellis, K. Malla, and A. M. Costello. 1998. Factors affecting home delivery in the Kathmandu Valley, Nepal. Health Policy and Planning 13 (2): 152-158.

Carlough, M. 1997. "More than hospital is needed in Nepal." Safe Motherhood Newsletter 24 (2): 9-10.

Central Bureau of Statistics. 1993. Population Census- 1991: Social Characteristics, Tables Vol. I, Part VII. Kathmandu, Nepal: His Majesty’s Government, National Planning Commission Secretariat.

Central Bureau of Statistics. 1995. Population Monograph of Nepal.

Kathmandu, Nepal: His Majesty's Government, National Planning Commission Secretariat.

Central Bureau of Statistics. 2006. Nepal in Figures, 2006. Nepal: National Planning Commission Secretariat, Government of Nepal. 
Dali, S. M., M. Thapa and S. Shrestha. 1992. "Educating Nepalese women to provide improved care for their child-bearing daughters-in-law. (Reader's Forum)." World Health Forum 13: 353-354.

Fricke, Tom. 1986. Himalayan Households: Tamang Demography and Domestic Processes. Ames, USA: Iowa State University Press.

Graham, W., W. Brass and R. W. Snow. 1989. "Estimating maternal mortality: The sisterhood method." Studies in Family Planning 20 (3): 125-135.

Hay, M. Cameron. 1999. "Dying mothers: Maternal mortality in rural Indonesia." Medical Anthropology, 18: 243-279.

Hieu, D. T., R. Hanenberg, T. H. Vack, D. Q. Vinh, and D. Sokal. 1999. "Maternal mortality in Vietnam in 1994-95." Studies in Family Planning 30 (4): 329-338.

Hitchcock, J. T. 1980. A Mountain Village in Nepal. USA: Holt, Rinehart and Winston.

International Centre for Integrated Mountain Development (ICIMOD). 1997. Districts of Nepal: Indicators of Development. Kathmandu, Nepal: ICIMOD.

Jones, R. L. and S. K. Jones. 1976. The Himalayan Woman: A Study of Limbu Women in Marriage and Divorce. California, USA: Mayfield.

Journal of Nepal Medical Association (JNMA). 1994. Editorial, 32 (111).

Justice, Judith. 1986. Policies Plans and People: Culture and Health Development in Nepal. California, USA: University of California Press.

Kipp, Eva. 1995. Bending Bamboo Changing Winds. Delhi, India: Book Faith India.

Levitt, M. J. 1993. A Systematic Study of Birth and Traditional Birth Attendants in Nepal (2nd Edition). Nepal: John Snow Inc./USAID.

Li, X. F., J. A. Fortney, M. Kotelchuck, and L. H. Glover. 1996. "The postpartum period: The key to maternal mortality." International Journal of Gynecology and Obstetrics 54: 1-10. 
Juhee Suwal

Messerschmidt, D. A. 1976. The Gurungs of Nepal: Conflict and Change in a Village Society. Warminster, England: Aris \& Phillips Ltd.

Ministry of Health. 1996/97. Annual Report. Nepal: Department of Health Services, Ministry of Health.

Ministry of Health. 1997a. Nepal Family Health Survey, 1996. Nepal: Family Health Division, Department of Health Services, Ministry of Health.

Ministry of Health. 1997b. Health Information Bulletin, Volume 10. Nepal: Policy, Planning, Foreign Aid and monitoring Division, Ministry of Health.

Ministry of Health. 1998. Maternal Mortality and Morbidity Study. Nepal: Family Health Division, Department of Health Services, Ministry of Health.

Mullany, Britta C., Michelle J. Hindin and Stan Becker. 2005. "Can women's autonomy impede male involvement in pregnancy health in Katmandu, Nepal?" Social Science and Medicine 61 (9): 1993-2006.

Neidell, S. G., B. B. Niraula, S. P. Morgan, and S. Stash. 1998. "Moslem and non-Moslem fertility differences in the Eastern Terai of Nepal."

Contributions to Nepalese Study 25 (Special Issue): 109-128.

Nepal Demographic and Health Survey 2006. 2007. Kathmandu, Nepal: Population Division, Ministry of Health and Population, Government of Nepal in Collaboration with New ERA, Kathmandu, USAID, and Macro International Inc., Maryland, U.S.A.

Niraula, B. B. 1994. "Use of health services in hill villages in Central Nepal." Health Transition Review 4 (2): 151-2166.

Okonofua, F. E., A. Abejide, and R. A. Makanjuola. 1992. "Maternal mortality in Ile-Ife, Nigeria: A study of risk factors." Studies in Family Planning 23 (5): 319-324.

Presern, C. 1992. "Maternal mortality in Nepal." Nursing Times (Feb. 26) 88 (9): 64-65.

Rijal, Sangeeta. 2006. "Maternal deaths go down dramatically.” Available at http://www.kantipuronline.com/kolnews.php?nid=95221. Accessed on December 21, 2006. 
Shiffman, J. 2000. "Can poor countries surmount high maternal mortality?" Studies in Family Planning 31 (4): 274-289.

Sigdel, S. 1998. Primary Health Care Provision in Nepal. Kathmandu, Nepal: Sangita Sigdel.

Suwal, Juhee V. 2001. "The main determinants of infant mortality in Nepal." Social Science and Medicine 53 (12): 1667-1681.

Thapa, S., P. J. Thapa, and N. Shrestha. 1994. "Abortion in Nepal: Emerging insights.” Journal of Nepal Medical Association 32 (111): 175-190.

Thapa, S. 1996. "Challenges to improving maternal health in rural Nepal." The Lancet 347 (9010): 1244-1246.

The Kathmandu Post (Newspaper, Daily). 1997. "Induced abortion causes half a maternity deaths" (Report). Available at http://www.nepalnews.com. Accessed on Mar17, 1997.

The Kathmandu Post (Newspaper, Daily). 1999. "Muslims compete for children." Available at http://www.nepalnews.com. Accessed on November 14, 1999.

2006 Nepal Demographic and Health Survey: Fact Sheet. 2007. Available at http://www.measuredhs.com/pubs/pdf/GF7/Nepal_Fact_Sheet.pdf. Accessed on May 29, 2007.

United Nations. 2000. The World's Women, 2000: Trends and Statistics. New York, USA: United Nations.

Weston, L. 1986. Reducing Maternal Deaths in Developing Countries. World Bank: Population, Health and Nutrition Department.

Winikoff, B. and M. Sullivan. 1987. "Assessing the role of family planning in reducing maternal mortality." Studies in Family Planning 18 (3): 128143.

World Bank. 1989. Nepal Social Sector Strategy Review, Vol. 2. Nepal: World Bank. 
Juhee Suwal

Appendix 1

Specification of Variables for the Logistic Regression Analysis

\begin{tabular}{|c|c|c|}
\hline Variables & Levels & $\begin{array}{c}\text { Values for Dummy } \\
\text { Variables }\end{array}$ \\
\hline
\end{tabular}

Region

$\begin{array}{ll}\text { Far Western } & 0=\text { reference category } \\ \text { Eastern } & 1 \text { versus reference } \\ \text { Central } & 1 \text { vs reference } \\ \text { Western } & 1 \text { vs reference } \\ \text { Mid-Western } & 1 \text { vs reference }\end{array}$

Place of Residence

$\begin{array}{ll}\text { Rural } & 0=\text { reference } \\ \text { Urban } & 1\end{array}$

Religion

$\begin{array}{ll}\text { Hindu } & 0=\text { reference category } \\ \text { Buddhist } & 1 \text { versus reference } \\ \text { Muslim } & 1 \text { vs reference } \\ \text { Other } & 1 \text { vs reference }\end{array}$

Ethnicity

$\begin{array}{ll}\text { Brahmin+Chhetri } & 0=\text { reference category } \\ \text { Newar } & 1 \text { versus reference } \\ \text { Mongoloid } & 1 \text { vs reference } \\ \text { Muslim } & 1 \text { vs reference } \\ \text { Occupational } & 1 \text { vs reference } \\ \text { Others } & 1 \text { vs reference }\end{array}$

Age at death
12-19
20-34
$35-49$
1 versus reference
1 versus reference
$0=$ reference category

Number of births given before a female sibling died

$\begin{array}{ll}\text { No child } & 1 \text { versus reference } \\ \text { One child } & 1 \text { vs reference } \\ 2-3 \text { children } & 1 \text { vs reference } \\ 4 \text { or more children } & 0=\text { reference category }\end{array}$

